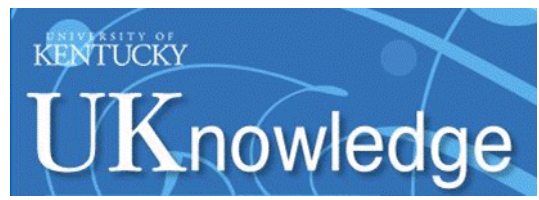

University of Kentucky

UKnowledge

\title{
Hypercholesterolemia Accelerates Both the Initiation and Progression of Angiotensin II-induced Abdominal Aortic Aneurysms
}

Jing Liu

University of Kentucky

Hisashi Sawada

University of Kentucky, hisashi.sawada@uky.edu

Deborah A. Howatt

University of Kentucky, deborah.howatt@uky.edu

Jessica J. Moorleghen

University of Kentucky, jjmoorl@uky.edu

Olga A. Vsevolozhskaya

University of Kentucky, vsevolozhskaya@uky.edu

Follow this and additional works at: https://uknowledge.uky.edu/pharmacol_facpub

Part of the Biostatistics Commons, Medical Nutrition Commons, Medical Pharmacology Commons, See next page for additional authors

and the Medical Physiology Commons

Right click to open a feedback form in a new tab to let us know how this document benefits you.

\section{Repository Citation}

Liu, Jing; Sawada, Hisashi; Howatt, Deborah A.; Moorleghen, Jessica J.; Vsevolozhskaya, Olga A.; Daugherty, Alan; and Lu, Hong S., "Hypercholesterolemia Accelerates Both the Initiation and Progression of Angiotensin II-induced Abdominal Aortic Aneurysms" (2020). Pharmacology and Nutritional Sciences Faculty Publications. 97. https://uknowledge.uky.edu/pharmacol_facpub/97

This Article is brought to you for free and open access by the Pharmacology and Nutritional Sciences at UKnowledge. It has been accepted for inclusion in Pharmacology and Nutritional Sciences Faculty Publications by an authorized administrator of UKnowledge. For more information, please contact UKnowledge@lsv.uky.edu. 


\section{Hypercholesterolemia Accelerates Both the Initiation and Progression of Angiotensin II-induced Abdominal Aortic Aneurysms}

Notes/Citation Information

Published in Annals of Vascular Medicine \& Research, v. 7, no. 1, 1099, p. 1-5.

(c) 2020 Liu J, et al.

Open Access Publication by JSciMed Central is licensed under a Creative Commons Attribution 4.0 International License.

\section{Authors}

Jing Liu, Hisashi Sawada, Deborah A. Howatt, Jessica J. Moorleghen, Olga A. Vsevolozhskaya, Alan Daugherty, and Hong S. Lu 
Preclinical Research

\section{Hypercholesterolemia}

\section{Accelerates Both the Initiation} and Progression of Angiotensin Il-induced Abdominal Aortic

\section{Aneurysms}

Jing Liü ${ }^{1}$, Hisashi Sawada ${ }^{2}$, Deborah A. Howatt ${ }^{2}$, Jessica J.

Moorleghen $^{2}$, Olga Vsevolozhskaya ${ }^{3}$, Alan Daugherty ${ }^{1,2,4}$, and

Hong S. Lu ${ }^{1,2,4 *}$

${ }^{I}$ Department of Pharmacology and Nutritional Sciences, University of Kentucky, USA

${ }^{2}$ Saha Cardiovascular Research Center, University of Kentucky College of Medicine, USA

${ }^{3}$ Department of Biostatistics, University of Kentucky, USA

${ }^{4}$ Department of Physiology, University of Kentucky, USA

\section{*Corresponding author}

Hong S. Lu, Saha Cardiovascular Research Center, University of Kentucky College of Medicine, BBSRB Room B249, 741 South Limestone, Lexington, KY 40503-0509, USA, Tel: 859-323-4639; Email: Hong.Lu@uky.edu

Submitted: 06 January 2020

Accepted: 10 January 2020

Published: 13 January 2020

ISSN: 2378-9344

Copyright

(c) 2020 Liu J, et al.

\section{OPEN ACCESS}

\section{Keywords}

- Abdominal aortic aneurysms

- Angiotensin II

- Plasma cholesterol

- Hypercholesterolemia

- LDL receptor

\begin{abstract}
Objective: This study determined whether hypercholesterolemia would contribute to both the initiation and progression of angiotensin (Ang) Il-induced abdominal aortic aneurysms (AAAs) in mice.

Methods and Results: To determine whether hypercholesterolemia accelerates the initiation of AAAs, male low-density lipoprotein (LDL) receptor -/- mice were either fed one week of Western diet prior to starting Angll infusion or initiated Western diet one week after starting Angll infusion. During the first week of Angll infusion, mice fed normal diet had less luminal expansion of the suprarenal aorta compared to those initiated Western diet after the first week of Angll infusion. The two groups achieved comparable luminal dilation on week 2 through week 6 of Angll infusion as monitored by ultrasound. To determine whether hypercholesterolemia contributed to the progression of established AAAs, male LDL receptor -/- mice were fed Western diet and infused with Angll for 4 weeks. Mice with established AAAs were then stratified into two groups based on luminal diameters measured by ultrasound. While Angll infusion was continued for another 8 weeks in both groups, mice in one group were continuously fed Western diet, but diet in the other group was switched to normal laboratory diet. In the latter group, plasma cholesterol concentrations were reduced rapidly to approximately $500 \mathrm{mg} / \mathrm{dl}$ within one week after the diet was switched from Western diet to normal laboratory diet. Luminal expansion progressed constantly in mice continuously fed Western diet, whereas no continuous expansion was detected in mice that were switched to normal laboratory diet.

Conclusion: Hypercholesterolemia accelerates both the initiation of AAAs and progression of established AAAs in Angll-infused male LDL receptor -/mice.

Clinical Relevance: Hypercholesterolemia is modestly associated with AAAs in observational or retrospective clinical studies. It is not feasible to study whether hypercholesterolemia contributes to the initiation of AAAs or progression of established AAAs in human. This study using Angll-induced AAA mouse model provides solid evidence that hypercholesterolemia contributes to both the initiation and progression of AAAs, supporting that statin therapy at any stage of AAA development may be beneficial to hypercholesterolemic patients with AAAs.
\end{abstract}

\section{INTRODUCTION}

Hypercholesterolemia augments development of angiotensin II (AngII)-induced abdominal aortic aneurysms (AAAs) in male mice [1-6]. This has been most commonly demonstrated in male low-density lipoprotein (LDL) receptor -/- mice fed a Western diet for one week prior to starting AngII infusion [7]. This one week of Western diet feeding leads to profound increases of plasma cholesterol concentrations to more than $1,000 \mathrm{mg} / \mathrm{dl}$ [3]. It is unclear whether a pre-existing hypercholesterolemic status is important to the initiation of AngII-induced AAAs, or it is critical for the progression of pre-existing AAAs.

Plasma total cholesterol concentrations are below $300 \mathrm{mg} /$ dl in LDL receptor -/- mice fed normal laboratory diet, but increase to more than $1,000 \mathrm{mg} / \mathrm{dl}$ within a week of Western diet feeding [3,8-10]. This LDL receptor -/- mouse in combination with diet manipulation provides a model to determine whether hypercholesterolemia contributes to the initiation and progression of AngII-induced AAAs. In this study using male LDL 
receptor -/- mice, we determined whether hypercholesterolemia would promote the initiation of AngII-induced AAAs, and whether maintaining hypercholesterolemia would modulate the progression of established AAAs.

\section{MATERIAL AND METHODS}

The raw data that support the findings reported in this manuscript are available from the corresponding author upon reasonable request.

\section{Mice and diet}

Male low-density lipoprotein (LDL) receptors -/- mice (8 weeks old) were purchased from The Jackson Laboratory (Stock \# 2207; Bar Harbor, ME, USA). Mice were housed in individually vented cages (5 mice/cage) on a light:dark cycle of 14:10 hours. The cage bedding was Teklad Sani-Chip bedding (Cat \# 7090A; Envigo, Madison, WI, USA). Mice were fed a normal rodent laboratory diet (Diet \# 2918; Envigo) and given drinking water from a reverse osmosis system ad libitum. To induce hypercholesterolemia, mice were fed a Western diet supplemented with saturated fat extracted from milk (21\% wt/ $\mathrm{wt})$ and cholesterol $(0.15 \% \mathrm{wt} / \mathrm{wt}$ supplemented and $0.05 \% \mathrm{wt} /$ wt from the fat source; Diet \# TD.88137; Envigo). Mice died of any reason prior to termination were excluded for data analyses.

In this study, we only used male mice because female LDL receptor -/- mice have very low incidence of AngII-induced AAAs $[3,11,12]$. All mouse experiments reported in this manuscript were performed with the approval of the University of Kentucky Institutional Animal Care and Use Committee (University of Kentucky IACUC protocol number: 2006-0009).

\section{Mini Osmotic Pump Implantation and Angiotensin II Infusion}

To induce AAAs, mice were infused with 1,000 ng/ kg/min of AngII (Cat \# H-1705; Bachem, Torrance, CA, USA) subcutaneously via Alzet mini osmotic pumps (Alzet Model \# 2006; Durect Corp, Cupertino, CA, USA). ${ }^{7}$ In first study (Figure 1A), one group of mice started Western diet one week prior to AngII infusion (WD group), whereas the other group started this Western diet one week after initiating AngII infusion (ND - WD group). AngII infusion duration was 6 weeks for both groups.

In second study (Figure 2A); all mice were fed Western diet for one week prior to AngII infusion. Lumen diameters of suprarenal aortas were measured using noninvasive high frequency ultrasound system (Vevo 2100 with MS550D; FUJIFILM VisualSonics, Toronto, ON, Canada) at baseline and on day 28 of AngII infusion. AAAs were defined as $50 \%$ or more increase of the maximal lumen diameter of the suprarenal aorta on day 28 compared to the baseline (day 0). Based on luminal diameter measurements, mice exhibiting AAAs were stratified into two groups, and then either continuously fed Western diet (WD group) or switched to normal laboratory diet (WD - ND group). These two groups were infused with AngII for an additional 8 weeks. The entire duration of AngII infusion was 12 weeks achieved by implanting two mini osmotic pumps separately (Alzet Model \# 2006): One pump was implanted on day 0 and replaced by a second pump on day 43 . The second pump was
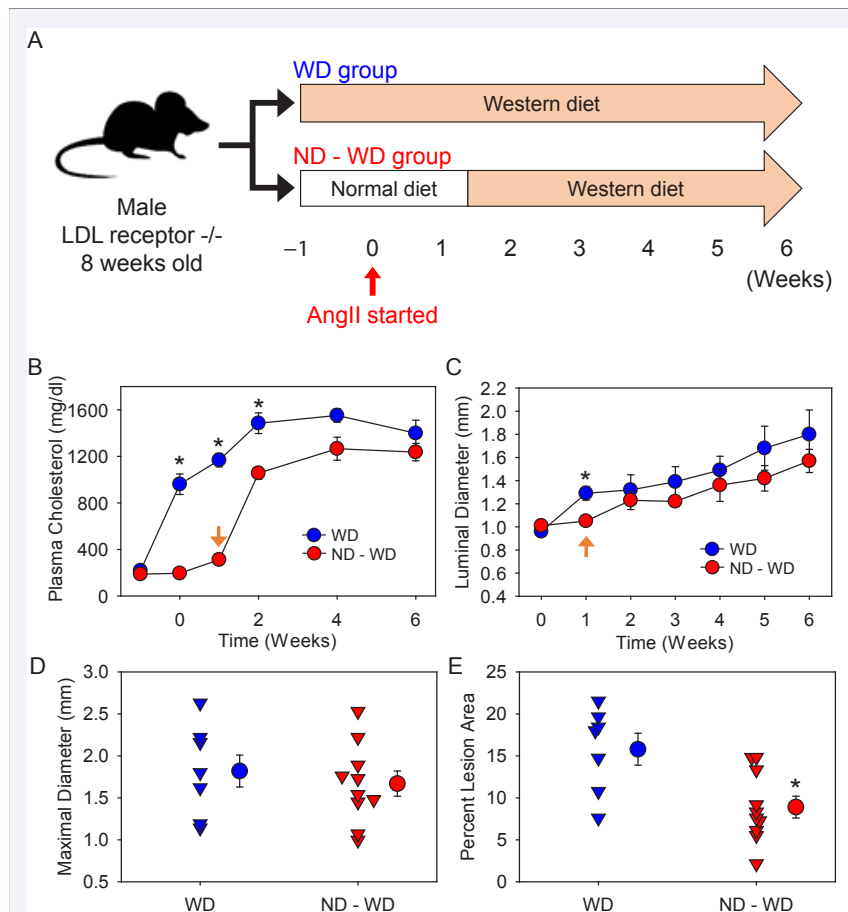

Figure 1 Hypercholesterolemia accelerated the initiation of AngII-induced AAAs in male LDL receptor -/- mice. (A) Mice in WD group initiated Western diet feeding one week prior to AngII infusion, and mice in ND - WD group initiated Western diet one week after starting AngII infusion. The duration of AngII infusion was 6 weeks. (B) Plasma cholesterol concentrations were measured using an enzymatic method. $* \mathrm{P}<0.001,=0.007$, and $<0.001$ between the two groups on Week 0,1, and 2, respectively. (C) Maximal luminal diameters of suprarenal aortas were measured using ultrasound.* $\mathrm{P}=$ 0.004 on week 1 . The orange arrow in (B) and (C) indicates the start of Western diet feeding in ND - WD group. (D) Maximal outer diameters of suprarenal aortas were measured using an ex vivo method. (E) Atherosclerosis was measured by an en face method. ${ }^{*} \mathrm{P}=0.008$. Triangles are values from individual mice. Circles represent means and error bars represent SEM.

preincubated in saline at $37^{\circ} \mathrm{C}$ for more than 60 hours to permit immediate delivery of AngII after implantation of pumps in mice.

\section{Ultrasonography}

Luminal diameters of suprarenal aortas were measured using a Vevo 2100 ultrasound imaging system at indicated intervals [13]. Mice were anesthetized with isoflurane and restrained in a supine position. Short-axis scan was performed from the level of left renal artery moving vertically up to the suprarenal region. One hundred frames of cine loops were acquired and the maximal luminal diameter of the suprarenal aortic region was measured on images during aortic dilation phase. Luminal diameters were measured by one investigator, and verified by another investigator independently who were blind to study groups.

\section{Plasma cholesterol measurements}

During each study, mice were bled consciously with submandibular bleeding. At termination mice were anesthetized using ketamine/xylazine cocktail, and blood samples were harvested by right ventricular puncture. All blood samples 


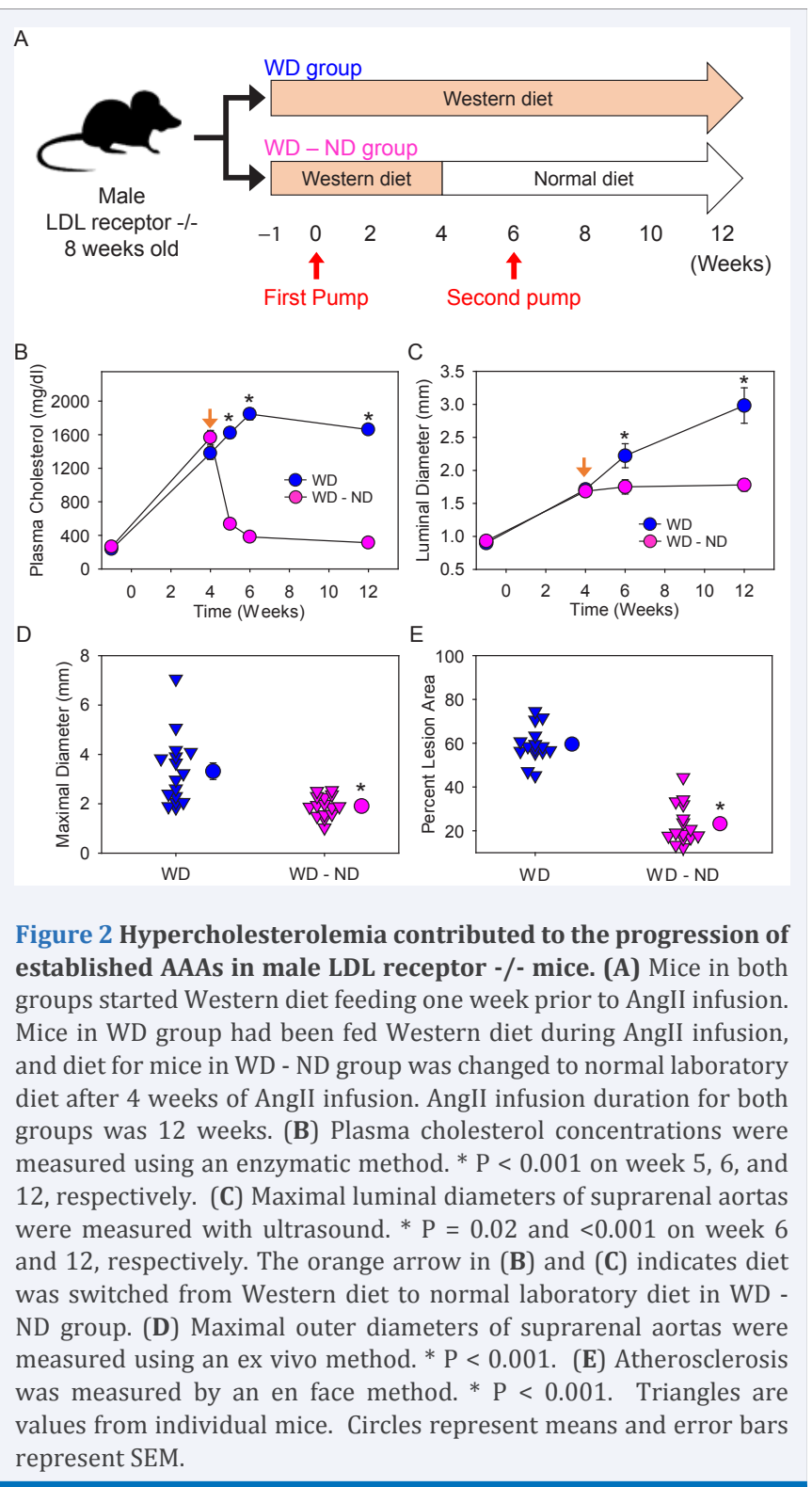

were collected with EDTA (final concentration: $1.8 \mathrm{mg} / \mathrm{ml}$ ) and centrifuged at $400 \mathrm{~g}$ for 20 minutes, $4^{\circ} \mathrm{C}$ to prepare plasma. Plasma cholesterol concentrations were measured using an enzymatic kit (Cat \# 439-17501; Wako Chemicals USA, Richmond, VA, USA).

\section{Quantification of aortic dilation and atherosclerosis}

Aortas were dissected, fixed, cleaned, and pinned. Maximal outer diameter of the suprarenal aorta was measured ex vivo as a parameter for aortic dilation using Image-Pro software (Version 7; Media Cybernetics, Bethesda, MD, USA).

Thoracic aortas were cut open and pinned for quantification of intimal area and atherosclerotic lesion area in the ascending aorta, aortic arch and the proximal descending aorta using an en face technique $[14,15]$. Atherosclerotic lesions, calculated as percent lesion area (lesion area/intimal area x 100\%), were compared between groups following the recommended approach described in the AHA statement [16].

\section{Statistical analyses}

Data are represented as means \pm standard errors of means (SEM). To compare two groups on a continuous variable after termination, unpaired two-sided Student's $t$ test was performed for normally distributed and equally variant values and Mann-Whitney rank sum test was used for variables not passing normality or equal variance test. Plasma cholesterol concentrations and luminal diameters of suprarenal aortas measured by ultrasonography at a series of time points were analyzed using linear mixed-effects models to compare trends over time among the sub-groups within the cohort, with random effects accounting for within-animal correlation. In general, unstructured correlation matrix with unequal variances was assumed to account for dependence among observations over time and within mice. Models were built using $\mathrm{R}$ version 3.3.2 statistical software. $\mathrm{P}<0.05$ was considered statistically significant.

\section{RESULTS}

\section{Hypercholesterolemia accelerated the initiation of AngII-induced AAAs}

Male LDL receptor -/- mice ( $\mathrm{N}=10$ /group) were randomized into two groups: WD group initiated Western diet one week prior to AngII infusion, and ND - WD group initiated this diet one week after AngII infusion was started (Figure 1A). Three mice in WD group were excluded for data analysis due to aortic rupture. Plasma cholesterol concentrations increased rapidly to approximately $1,000 \mathrm{mg} / \mathrm{dl}$ prior to the start of AngII infusion in WD group, whereas plasma cholesterol concentrations remained significantly lower within the first two weeks of AngII infusion in ND - WD group (Figure 1B). During the first week of AngII infusion, maximal luminal diameters of suprarenal aortas were smaller in ND - WD group than in WD Group as determined by ultrasonography $\mathrm{P}=0.004$. Luminal diameters became comparable between the two groups on $2-6$ weeks of AngII infusion (Figure 1C), as were also validated by ex vivo measurements after termination (Figure 1D). Consistent with the less duration of hypercholesterolemia, atherosclerotic lesions were smaller in ND - WD group than in WD group (Figure 1E).

\section{Hypercholesterolemia augmented the progression of established AngII-induced AAAs}

Seventy-nine male LDL receptors -/- mice were fed Western diet for one week prior to AngII infusion. The interval of AngII infusion was 4 weeks when Western diet continued. Eight mice died of aortic rupture during the 4 weeks of AngII infusion. Four weeks after AngII infusion 33 mice of the remaining 71 mice were stratified into two groups based on maximal luminal diameters $(\geq$ $50 \%$ than baseline) of suprarenal aortas measured by ultrasound. Mice in WD group were fed Western diet continuously and diet for WD - ND group was changed from Western diet to normal laboratory diet (Figure 2A). AngII infusion continued for another 8 weeks among these 33 mice. Two mice were excluded for data analysis due to abdominal aortic rupture. Therefore, 16 mice in WD group and 15 mice in WD - ND group were included for data analyses. Plasma cholesterol concentrations decreased rapidly in WD - ND group within one week after diet change and remained 
low during the remaining interval of AngII infusion (Figure 2B). Maximal luminal diameters of suprarenal aortas continuously increased in WD group, but remained constant during the rest 8 weeks of AngII infusion in WD - ND group (Figure 2C). This significant effect of aortic diameters detected using ultrasound was confirmed after termination by ex vivo measurements (Figure 2D). Consistent with attenuation of hypercholesterolemia, atherosclerotic lesion sizes were smaller in WD - ND group than in WD group (Figure 2E).

\section{DISCUSSION}

This study has demonstrated that hypercholesterolemia accelerates the initiation of AAAs and augments the progression of established AAAs in AngII-infused mice. This was demonstrated using male LDL receptor -/- mice fed normal laboratory diet or Western diet that rapidly change plasma cholesterol concentrations [3]. This study not only confirmed previous reports that Western diet feeding quickly increased plasma cholesterol concentrations $[3,8,10]$, but also provided evidence that plasma cholesterol concentrations reduced promptly after Western diet was withdrawn in LDL receptor -/- mice.

In this study, we used atherosclerosis as a "positive" control when we compared abdominal aortic dilation between groups because atherosclerosis has positive association with the magnitude and duration of hypercholesterolemia [3,16,17]. Mice with either delayed Western diet feeding or removal of Western diet had less atherosclerotic lesions, which were consistent with lower plasma cholesterol concentrations or shorter period of hypercholesterolemia. In contrast, the magnitude of hypercholesterolemia did not affect development of AngIIinduced AAAs, but removal of hypercholesterolemia attenuated the progression of established AAAs. These results are consistent with our previous findings that hypercholesterolemia augmenting AngII-induced AAAs has a threshold effect independent of the absolute concentration of plasma total cholesterol [3]. In addition, the present study provides evidence that hypercholesterolemia accelerates AngII-induced AAAs during both the initiative and the progressive stages. These findings support that inhibition of hypercholesterolemia is critical to prevent AAA development and attenuate the progression of established AAAs.

Many studies used apolipoprotein E deficient mice to explore mechanisms of AngII-induced AAAs (a few examples from a large number of publications [2,18-22]. This hypercholesterolemic mouse strain is modestly hypercholesterolemic and does not need Western diet to accelerate AngII-induced AAAs [3]. It appears that this mouse strain leads to higher incidence and mortality of AAAs, compared to LDL receptor -/- mice, although plasma cholesterol concentrations in apolipoprotein E -/- mice fed normal laboratory diet are much lower $(\sim 300-400 \mathrm{mg} / \mathrm{dl})$ compared to LDL receptor -/- mice fed Western diet (>1000 mg/ dl), ${ }^{3}$ implicating more complex mechanisms of AngII-induced AAAs in apolipoprotein E -/- mice. Therefore, LDL receptor -/mice have benefits to study contributions of hypercholesterolemia and its related mechanisms to AngII-induced AAAs.

The present study provides guide for using AngII-induced AAA model: A pre-existing hypercholesterolemic condition accelerates AngII-induced AAAs in LDL receptor -/- mice. Therefore, our standard protocol to feed mice one week of Western diet prior to AngII infusion is optimal. ${ }^{7}$ Second, to continuously feed Western diet in LDL receptor -/- mice during AngII infusion is suggested since hypercholesterolemia is important for the progression of established AAAs. Dissecting effects of hypercholesterolemia in the human disease is a cost, effort, and time-consuming task, which involves many uncontrolled compound factors. Beyond being a guide how to use this AngII-induced AAA mouse model appropriately, this study, combined with our previous studies, also provides insights into understanding whether and how hypercholesterolemia contributes to AAAs in humans [3,23,24].

\section{FUNDING SOURCE}

The authors' research work was supported by the National Institutes of Health under award number R01HL133723 and HL139748. Hisashi Sawada is supported by an American Heart Association postdoctoral fellowship (18POST33990468). The content in this manuscript is solely the responsibility of the authors and does not necessarily represent the official views of the National Institutes of Health.

\section{REFERENCES}

1. Daugherty A, Cassis L. Chronic angiotensin II infusion promotes atherogenesis in low density lipoprotein receptor -/- mice. Ann N Y Acad Sci. 1999; 892: 108-118.

2. Daugherty A, Manning MW, Cassis LA. Angiotensin II promotes atherosclerotic lesions and aneurysms in apolipoprotein E-deficient mice. J Clin Invest. 2000; 105: 1605-1612.

3. Liu J, Lu H, Howatt DA, Balakrishnan A, Moorleghen JJ, Sorci-Thomas $\mathrm{M}$, et al. Associations of apoAI and apoB-containing lipoproteins with AngII-induced abdominal aortic aneurysms in mice. Arterioscler Thromb Vasc Biol. 2015; 35: 1826-1834.

4. Lu H, Howatt DA, Balakrishnan A, Graham MJ, Mullick AE, Daugherty A. Hypercholesterolemia induced by a PCSK9 gain-of-function mutation augments angiotensin II-induced abdominal aortic aneurysms in C57BL/6 mice. Arterioscler Thromb Vasc Biol. 2016; 36: 1753-1757.

5. Deng GG, Martin-McNulty B, Sukovich DA, Freay A, Halks-Miller M, Thinnes $\mathrm{T}$, et al. Urokinase-type plasminogen activator plays a critical role in angiotensin II-induced abdominal aortic aneurysm. Circ Res. 2003; 92: 510-517.

6. Uchida HA, Poduri A, Subramanian V, Cassis LA, Daugherty A. Urokinase-type plasminogen activator deficiency in bone marrowderived cells augments rupture of angiotensin II-induced abdominal aortic aneurysms. Arterioscler Thromb Vasc Biol. 2011; 31: 28452852.

7. Lu H, Howatt DA, Balakrishnan A, Moorleghen JJ, Rateri DL, Cassis LA, et al. Subcutaneous angiotensin II infusion using osmotic pumps induces aortic aneurysms in mice. J Vis Exp. 2015; 103: e53191.

8. Ishibashi S, Goldstein JL, Brown MS, Herz J, Burns DK. Massive xanthomatosis and atherosclerosis in cholesterol-fed low density lipoprotein receptor-negative mice. J Clin Invest. 1994; 93: 18851893.

9. Tsukamoto K, Tangirala RK, Chun S, Usher D, Pure E, Rader DJ. Hepatic expression of apolipoprotein $\mathrm{E}$ inhibits progression of atherosclerosis without reducing cholesterol levels in LDL receptor-deficient mice. Mol Ther. 2000; 1: 189-194.

10. Bjorklund MM, Hollensen AK, Hagensen MK, Dagnaes-Hansen F, Christoffersen C, Mikkelsen JG, et al. Induction of atherosclerosis in mice and hamsters without germline genetic engineering. Circ Res. 
OSciMedCentral

2014; $114: 1684-1689$.

11. Robinet P, Milewicz DM, Cassis LA, Leeper NJ, Lu HS, Smith JD. Consideration of sex differences in design and reporting of experimental arterial pathology studies-Statement From ATVB Council. Arterioscler Thromb Vasc Biol. 2018; 38: 292-303.

12. Henriques T, Zhang X, Yiannikouris FB, Daugherty A, Cassis LA Androgen increases AT1a receptor expression in abdominal aortas to promote angiotensin II-induced AAAs in apolipoprotein E-deficient mice. Arterioscler Thromb Vasc Biol. 2008; 28: 1251-1256.

13. Sawada H, Chen JZ, Wright BC, Moorleghen JJ, Lu HS, Daugherty A Ultrasound imaging of the thoracic and abdominal aorta in mice to determine aneurysm dimensions. J Vis Exp. 2019; e59013.

14. Daugherty A, Whitman SC. Quantification of atherosclerosis in mice. Methods Mol Biol. 2003; 209: 293-309.

15. Daugherty A, Rateri DL. Development of experimental designs for atherosclerosis studies in mice. Methods. 2005; 36: 129-138.

16. Daugherty A, Tall AR, Daemen MJAP, Falk E, Fisher EA, GarciaCardena G, et al. Recommendation on design, execution, and reporting of animal atherosclerosis studies: A Scientific Statement from the American Heart Association. Arterioscler Thromb Vasc Biol. 2017; 37: e131-e157.

17. Ference BA, Ginsberg HN, Graham I, Ray KK, Packard CJ, Bruckert E, et al. Low-density lipoproteins cause atherosclerotic cardiovascular disease. 1. Evidence from genetic, epidemiologic, and clinical studies. A consensus statement from the European Atherosclerosis Society Consensus Panel. Eur Heart J. 2017; 38: 2459-2472.
18. Yoshihara T, Shimada K, Fukao K, Sai E, Sato-Okabayashi Y, Matsumori $\mathrm{R}$, et al. Omega 3 polyunsaturated fatty acids suppress the development of aortic aneurysms through the inhibition of macrophage-mediated inflammation. Circ J. 2015; 79: 1470-1478.

19. Umebayashi R, Uchida HA, Kakio Y, Subramanian V, Daugherty A, Wada J. Cilostazol attenuates angiotensin II-induced abdominal aortic aneurysms but not atherosclerosis in apolipoprotein E-deficient mice. Arterioscler Thromb Vasc Biol. 2018; 38: 903-912.

20. Deguchi JO, Huang H, Libby P, Aikawa E, Whittaker P, Sylvan J, et al. Genetically engineered resistance for MMP collagenases promotes abdominal aortic aneurysm formation in mice infused with angiotensin II. Lab Invest. 2009; 89: 315-326.

21. Moran CS, Biros E, Krishna SM, Wang Y, Tikellis C, Morton SK, et al. Resveratrol inhibits growth of experimental abdominal aortic aneurysm associated with upregulation of angiotensin-converting enzyme 2. Arterioscler Thromb Vasc Biol. 2017; 37: 2195-2203.

22. Sawada H, Hao H, Naito Y, Oboshi M, Hirotani S, Mitsuno M, et al. Aortic iron overload with oxidative stress and inflammation in human and murine abdominal aortic aneurysm. Arterioscler Thromb Vasc Biol. 2015; 35: 1507-1514.

23. Forsdahl SH, Singh K, Solberg S, Jacobsen BK. Risk factors for abdominal aortic aneurysms: a 7-year prospective study: the Tromso Study, 1994-2001. Circulation. 2009; 119: 2202-2208.

24. Chun KC, Teng KY, Chavez LA, Van Spyk EN, Samadzadeh KM, Carson JG, et al. Risk factors associated with the diagnosis of abdominal aortic aneurysm in patients screened at a regional Veterans Affairs health care system. Ann Vasc Surg. 2014; 28: 87-92. 